\title{
Living with Hypoglycemia
}

\author{
Marilyn D. Ritholz, PhD, Alan M. Jacobson, MD
}

OBJECTIVE: To increase understanding of the everyday experiences of hypoglycemia for patients with type 1 diabetes through the use of a narrative research approach.

SETTING: Center for diabetes treatment and research.

DESIGN: Cross-sectional assessment using a narrative research approach.

PATIENTS/PARTICIPANTS: Twenty outpatients (aged 21-30 years) diagnosed with type 1 diabetes for at least 10 years.

MEASUREMENTS AND MAIN RESULTS: Experiences of hypoglycemia were investigated during in-depth, semistructured interviews that were tape-recorded, transcribed, and analyzed to identify common themes. Self-report measures of depression (Revised Hamilton Rating Scale for Depression) and anxiety (State-Trait Anxiety Inventory) also were administered. Subjects reported the following common themes: interpersonal conflict including fears of dependency and loss of control and problems addressing concerns about hypoglycemia with significant others; difficulty making sense of their hypoglycemic behaviors in relation to their usual ways of functioning; and perceived lack of understanding by others, including physicians, about the emotional experiences of hypoglycemia. Subjects were neither clinically depressed nor anxious.

CONCLUSIONS: These findings suggest that type 1 diabetes patients' experiences of hypoglycemia negatively affect their interpersonal relationships and views of themselves. Hypoglycemia also was described as an extremely private experience that was rarely discussed with others. Patient education and professional support in the treatment of hypoglycemia are recommended to enhance treatment decision making for patients with type 1 diabetes.

KEY WORDS: hypoglycemia; type 1 diabetes; narrative research.

J GEN INTERN MED 1998;13:799-804.

$\mathbf{H}$ ypoglycemia is the most frequent side effect of insulin treatment and thus is a fact of life for people with type 1 diabetes. It causes both autonomic symptoms (nervousness, sweating, and hunger) and neuroglycopenic symptoms (confusion, weakness, and less frequently seizure or coma) and can lead to death. As treatment for diabetes moves toward the goal of maintaining blood glucose

Received from the Behavioral and Mental Health Research Section, Joslin Diabetes Center, The Children's Hospital, and The Department of Psychiatry, Harvard Medical School, Boston, Mass. (MDR, AMJ).

Address correspondence and reprint requests to Dr. Ritholz: Behavioral and Mental Health Unit, Joslin Diabetes Center, One Joslin Place, Boston, MA 02215. levels as close to the normal range as possible to delay microvascular complications, ${ }^{1}$ there is an increased number of patients who are in a state of hypoglycemic unawareness and who experience severe hypoglycemia. ${ }^{2,3} \mathrm{Al}-$ though hypoglycemic symptoms have been studied in the laboratory with the use of the insulin infusion clamp, ${ }^{4-7}$ and in quantitative studies using self-report questionnaires, ${ }^{8-11}$ personal accounts of patients' hypoglycemic experiences have not been reported.

Primary care medicine is increasingly utilizing a conceptual model that centers on the patient's experience as the salient feature of clinical care. ${ }^{12-14}$ Unless we can more attentively focus on a "thick description" 15 of hypoglycemia in which the details of the experience are recounted in the patient's own words, we cannot understand the actual and ordinary ways hypoglycemia affects the lives of patients with type 1 diabetes. Because of the centrality of hypoglycemia in the treatment of type 1 diabetes, ${ }^{16,17}$ better understanding of the patient's experience may enhance clinical decision making on the part of the physician. ${ }^{14}$

One method of gaining better understanding of the everyday experience of hypoglycemia is through qualitative research using narrative analysis. This approach is used in medical anthropology and sociology to explore patients' experiences of illness through the stories they tell and the meanings they attach to their experiences. ${ }^{18-30}$ Over the past 10 years, narrative research on chronic illness has increased markedly because "it is able to represent and reflect illness experiences in daily life." 18

A major goal of illness narratives is to learn more about the experience of an illness from the "insider" perspective. ${ }^{31}$ This perspective focuses on the subjective experience of living with an illness. In the present study, we explored such views of hypoglycemia.

The specific aims of this study were twofold: to allow 20 patients with type 1 diabetes to tell their experiences of hypoglycemia and the ways these experiences affect their everyday lives; and to increase health care professionals' awareness, sensitivity, and responsiveness to the hypoglycemic concerns of their patients.

\section{METHODS}

We studied 20 patients with type 1 diabetes whose names were selected from a computer-generated list of Joslin Diabetes Center patients aged 21 to 30 years. Patients were selected if they met the following criteria: type 1 diabetes for at least 10 years but no more than 18 years; no proliferative retinopathy, symptomatic neuropathy, nephropathy, or any other serious diabetic complication; no diagnosis of psychotic disorder; and no other serious major illness. These criteria were designed to select 
young adult patients who had type 1 diabetes for a sufficient number of years that they would have long-term experience with hypoglycemia. They also would not have had type 1 diabetes so many years that the lack of diabetic complications was out of the norm. Patients with diabetic complications and other serious medical or psychiatric illnesses were excluded so that these conditions would not color the patients' perceptions of their hypoglycemic experiences.

Potential subjects were mailed letters explaining the study. One week after receiving the letter, subjects were telephoned and asked about their willingness to participate in the study. Forty-nine letters were sent in order to obtain the 20 subjects used in the study.

Subjects met with the first author in an office at the Center. Data were collected using in-depth interviews that were tape-recorded and transcribed. Interviews lasted from 60 to 90 minutes. The in-depth interview included semistructured and demographic questions in which the term low blood sugar reaction often was used instead of hypoglycemia because of its greater familiarity to patients. Interview questions were constructed so that patients would give detailed descriptions of specific incidents of hypoglycemia in their everyday lives and their thoughts and feelings about these experiences. Whenever possible, patients were encouraged "to tell a story." In fact, in introductory letters, telephone calls, and at the start of the interview, patients were told that the interviewer wanted to hear their "stories of hypoglycemia."

Valid and reliable self-report scales, the Revised Hamilton Rating Scale for Depression (RHRSD) ${ }^{32}$ and the StateTrait Anxiety Inventory (STAI), ${ }^{33}$ were administered to obtain further information on the psychological functioning of the subjects.

Using standard qualitative methods, ${ }^{34-36}$ interview transcripts were analyzed by marking key words and phrases to identify the most prevalent themes or topics of relevance to the subjects. Themes were derived if they were present in at least $8(40 \%)$ of the 20 interviews. Furthermore, subjects were compared by Fisher's Exact Tests for the presence or absence of depression and anxiety and the presence or absence of the predominant themes.

\section{RESULTS}

\section{Sample Characteristics}

The characteristics of the subject sample and results of psychological assessments through standardized measures are presented in Table 1 . Subjects were highly educated. Seven of the 10 women held professional jobs, of which 5 were in the human services: nurse, social worker, dietitian, physical therapist, and teacher. Five of the 10 men had completed college. The men's jobs included 2 construction workers, 2 computer workers, 1 draftsman, and 1 salesman. Only one man was getting a graduate degree, and another man worked in emergency medical care. Group mean scores on the RHRSD and STAI (see Table 1) indicated subjects were not in the depressed and anxious ranges. However, the scores of six subjects (four men and two women) were in the minor depression range, and two other women reported taking antidepressant medications. In addition, three subjects (two of the six subjects in minor depression on RHRSD) scored on the STAI above 70th percentile rank for trait anxiety, and two subjects (the same women taking antidepressant medications) scored above the 70th percentile rank on state anxiety.

\section{Thematic Analysis}

Through subjects' personal accounts of hypoglycemia, the following common themes were identified: interpersonal conflict; discrepant views of the self; a private experience; and doctors' understanding. Within these overall themes, specific concerns were expressed about autonomy, control, identify, shame, and isolation.

No significant statistical differences were found in the presence or absence of any of the four identified themes between depressed subjects (RHRSD scores of minor depression or taking antidepressant medication) and nondepressed subjects. Too few subjects scored in the pathological anxiety range to make statistical comparisons by themes and presence of anxiety.

Table 1. Sample Characteristics

\begin{tabular}{|c|c|c|}
\hline Characteristic & Men & Women \\
\hline Number (\%) & $10(50)$ & $10(50)$ \\
\hline Mean age, years & 24.3 & 25.9 \\
\hline Completed college, $\%$ & 50 & 90 \\
\hline Mean age at diagnosis, years & 10.1 & 12.9 \\
\hline $\begin{array}{l}\text { Mean duration of diabetes, } \\
\text { years }\end{array}$ & 14.8 & 13.0 \\
\hline $\begin{array}{l}\text { Married or living with } \\
\text { significant other, \% }\end{array}$ & 30 & 30 \\
\hline $\begin{array}{l}\text { Mean hemoglobin } \mathrm{A}_{1 \mathrm{C}}, \%(\mathrm{SD})^{\ddagger} \\
{[4.0-6.0 \text { normal range }]}\end{array}$ & $9.3(1.3)$ & $8.4(0.9)$ \\
\hline $\begin{array}{l}\text { Report no warning signs for } \\
\text { hypoglycemia, \% }\end{array}$ & 40 & 40 \\
\hline $\begin{array}{l}\text { Report loss of consciousness } \\
\text { from hypoglycemia, } \%\end{array}$ & 40 & 30 \\
\hline $\begin{array}{l}\text { Report seizures from } \\
\text { hypoglycemia, \% }\end{array}$ & 20 & 10 \\
\hline $\begin{array}{l}\text { Depression, RHRSD mean } \\
\text { score (SD)* }\end{array}$ & $9.1(3.7)$ & $6.4(3.8)^{\dagger}$ \\
\hline Anxiety, STAI ${ }^{\ddagger}$ & & \\
\hline State score, mean (SD) & $28.6(6.2)$ & $31.1(7.7)$ \\
\hline Trait score, mean (SD) & $32.4(8.9)$ & $32.7(7.9)$ \\
\hline
\end{tabular}

${ }^{*}$ RHRSD indicates Revised Hamilton Rating Scale for Depression. Scores of $<10$ indicate not depressed; 11-16, minor depression; 17-25, major depression; and $>25$, severe depression.

${ }^{\dagger}$ Two female subjects were taking antidepressant medications.

${ }^{\ddagger}$ STAI indicates State-Trait Anxiety Inventory. On the STAI, the mean (SDs) for nonpatient, working adults aged 13-19 years are: state-anxiety for men $=36.5$ (10.22), women $=36.2$ (10.96); traitanxiety for men $=35.6$ (9.76), women $=36.2$ (9.53). 
Interpersonal Conflict. Ten subjects described situations in which they had difficulty accepting help from another person during a hypoglycemic episode. This situation was complicated by argumentative and sometimes hostile behaviors toward others, which were reported as occurring when blood sugar levels were too low. The following interpersonal story of a low blood sugar reaction was told by a 25-year-old woman:

\begin{abstract}
My boyfriend has had to deal with several [hypoglycemic episodes] recently. And initially, it was very tough on him.... I'd be upset that he recognized that I was low and I didn't, and that he was in control. And all sorts of issues that are tenuous in our relationship would start to come up. And I'd be very mean to him and shun him and tell him to just go away. Let me deal with it on my own. He'd feel incredibly hurt. And then I'd reject treatment from him, and he'd feel like I was calling our whole relationship off. And then once the sugar kicked in 20 minutes later, I was all happy and excited and cheery, and he couldn't understand it, and he'd say, "Wait, 20 minutes ago you were telling me to go. What is this?" He'd be very hurt. And so there'd be a big long discussion.

INTERVIEWER: What would you tell him?

That I wasn't really myself when I was doing that. That I was being defensive. And that it wasn't his fault. And that in a sense I didn't mean what I said. And that's very hard to take on his part, you know, to not believe that I didn't really mean what I was saying, and to accept that I can still love him but not want him to take care of me on the blood sugar side. So he's exchanged anecdotes with my mother, and I guess that's helped him.
\end{abstract}

As the above example demonstrates, interpersonal conflicts often arose when another person recognized the effects of hypoglycemia. When blood sugar levels fell too low, the subject was not able to recognize his/her own neuroglycopenic symptoms such as slurred speech, slowed thinking, or difficulty finding words, and therefore was often dependent on others to recognize the hypoglycemia. This situation sometimes led to resentment and conflict. In another example, a 23-year-old college-educated man described his difficulty when other people tried to assist him with his hypoglycemia in this way: "I get annoyed when people think they know more about me than I do."

Subjects' descriptions illustrated a clear tension between needing someone else's help when in a low blood sugar reaction and the fear of being dependent or out of control. This was particularly an issue for patients with severe hypoglycemia, which is defined by requiring the assistance of another person in its treatment. ${ }^{1}$ Moreover, it is important that diabetes requires meticulous self-care on a daily basis and self-sufficiency is encouraged by medical providers. Therefore, the need to have another's assistance in the treatment of hypoglycemia conflicts with this expectation of self-sufficiency.

Twelve subjects expressed their concerns about having family members or significant others witness, attempt to treat, and worry about their hypoglycemia. At times, guilt and a sense of overwhelming responsibility were re- ported as experienced by both subjects and their significant others. For example, a 24-year-old married woman stated her worst worry about her husband's reaction to her hypoglycemia as follows, "Maybe if I slipped too far, and I didn't wake up again, what would it do to him?" Another young man stated his concern for his mother in this way:

My mom gets anxious subtly. When I come out of it, I can tell that my mom sort of panicked. It kind of makes you feel bad that it happened. Not that I could have helped it. It's a funny kind of concerned feeling, and you don't like to see anybody like that. I know my mom is a strong person, but still her nerves can only take so much.

Attribution of responsibility in the prevention of hypoglycemia was presented as a complicated issue. At times subjects expressed feeling helpless to prevent hypoglycemia, while at other times they feel guilty, fearful, and self-blaming for not having prevented it. For example, a 27-year-old married woman described a mixture of impatience and concern in her husband's feelings with regard to her low blood sugar level when she said:

\begin{abstract}
I think it aggravates him a lot. My husband is very protective of me. He'll do little things like calling and checking during the day to make sure I'm alright. . . . So he's protective of me on the one hand, and on the other hand it aggravates him to no end whenever I have a reaction. He's like, "Okay, what happened this time? Let's get this straightened out. We don't want this to keep happening." I think it worries him. I think it scares him each time it happens. ... I feel guilty. I feel like I've disappointed him. I should have been trying harder or something like that.
\end{abstract}

Discrepant Views of the Self. Behaviors that occur as a result of hypoglycemia were often difficult to reconcile with subjects' everyday sense of self. Eight subjects reported feeling disconcerted and embarrassed by hypoglycemic behaviors they saw as alien to their sense of self. There was a discrepancy between their sense of self as a socialized, polite person and the more irritable and hostile self they became when hypoglycemic. There also was a discrepancy between their sense of self as a competent, intelligent, and aware person and their inability to focus, remember, or think clearly when hypoglycemic. During her interview, a lawyer stated,

You could be talking perfectly rationally with someone like I am now with you, and 2 minutes later I'm babbling like an idiot. And I don't know what's going on. That's very difficult to deal with and live with, especially when you're in social contacts or being an attorney, being in a courtroom or a deposition.

Another well-educated young woman talked about her embarrassment and confusion with regard to hypoglycemia in this way, "I think one thing that sort of bothers me about it is just how stupid I can feel, and it's like losing a major part of your person."

Subjects did not want other people to misinterpret their hypoglycemic behaviors as who they really were. 
They feared that others might perceive them as less capable and more impaired than they saw themselves or wanted to be seen. For example, a 29-year-old woman described her worst fear of what could happen during hypoglycemia as,

\begin{abstract}
being misunderstood for who I am or why I'm reacting the way I am. . . . Not so much my personality or anything to do with my attitude, but just my ability to do the job and handle pressure and to be present and to really be there. I don't want the low blood sugars or the diabetes to be seen as a disability.
\end{abstract}

A Private Experience. All subjects in this study perceived the experience of hypoglycemia as not understandable to people unless they had diabetes or hypoglycemia from other causes. They also reported that it was hard to find a way to describe their experiences, and that they rarely talked about hypoglycemia with anyone. One 25-year-old woman stated, "I'll just not discuss it. Like, why bring it up? It's too intimate a part of myself." Hypoglycemia therefore was kept to oneself, rarely discussed, and often even ignored as a major difficulty in the treatment of type 1 diabetes.

Some subjects stated that the autonomic signs of hypoglycemia were easier for others to understand than the psychological symptoms, which they felt were unique. A 23-year-old man reported: "You can't relate to a person what it feels like, just the inner feeling. You know they see the shakes, the sweating. I think they can relate to that. I don't think they can relate to the inner feeling." Without a common point of reference, subjects questioned whether empathy or understanding could develop. For example, one female subject stated the following:

It's just like there are things that people, unless they've experienced them, can't really understand. They can't sympathize. They can't empathize. . . . I mean most people can understand the concept of lips tingling or feeling shaky or having a headache or not being able to concentrate . . . but then also to know that with those things comes a loss of control and its symptoms and the mind frame and that makes a low blood sugar. That is what I think people, unless they've experienced it, can't understand.

Subjects expressed feelings that it also was difficult to communicate about hypoglycemia. Language was seen as falling short of being able to capture the experience of hypoglycemia. For example, one 25-year-old man stated,

I can't think of the words to really describe the pressure behind my eyes. So that's the best I come up with, but it's not really what it is. And the shaky knees isn't really shaky knees in any way at all. It's kind of a . . . I can't, I can't find the words.

Another young man said, "It's just that weakness feeling. . . . I just think it's too difficult to tell them, to put into words, just exactly how that feels." Through the stories subjects told, the loss of control and helplessness of hypoglycemia were made comprehensible, given language and form. The following narrative is an example of a "most remembered low blood sugar reaction":

I was away with a friend down on the Cape, and golfed all morning - my friend and I and his father. I had a splitting headache before the end of the day. Played 18 holes. I came down with this headache. We went back to the house. They were going to play tennis, and I said, "No, I'm just going to lie down and take a nap." I lay down. I don't know what the time frame was, but I just woke up sweaty and feeling weak, dizzy, not dizzy. I remember I got up. The mattress was on the ground. It didn't have a box spring. I got up, and boom I fell right back down. I was awake and I didn't pass out, but my body just seemed to go limp. I remember I couldn't put my arms in front of me. I just banged my head off the floor. . . . That's what I'll always remember. I was just banging my head because I couldn't stop myself. My mind just didn't tell me to put my hands up or something.

In the above narrative, hypoglycemia progressed from autonomic signs to confusion, and then to the subject's inability to protect himself. Through the ordinary details of this young man's story-i.e., the mattress on the ground with no box spring; his falling down; his not being able to put his arms up to stop himself from banging his head on the floor-he presented his helplessness and lack of control. The lack of connection between his thought and his behaviors was most disconcerting to him.

Doctors' Understanding. Nine subjects described the physicians who treat their diabetes as not inquiring about or understanding their subjective experiences of hypoglycemia. Their doctors were perceived as not asking about their emotional responses to hypoglycemic experiences or the ways hypoglycemia affected their feelings about themselves, their family relationships, or their work experiences. During his interview, one young man said, "I've never talked about it this way. It's the most I've ever talked about it in my life."

Subjects further described their physicians as almost solely concerned with the concrete details, the biomedical elements of hypoglycemia, i.e., what led up to it, how often it occurred, and what was done to treat it. A 23-yearold man talked about his encounter with his physician in this way, "I can't recall discussing a low blood sugar with him. I think he understands the results. The other part of it, I can't imagine he would know." Another 24-year-old man described his experiences of hypoglycemia with physicians as "number crunching." This was not said in a critical way, but rather "that's normally more what I go to him for help with, controlling it." He later added, "I guess I don't go to him for that [emotional/personal] kind of understanding."

Subjects seemed to accept their doctor's lack of inquiry into and understanding of their emotional experiences of hypoglycemia as what they expected from medical treatment. One young man stated that he "never really thought about" discussing his feelings with his physician, and another said, "I don't really tell my doctor much 
about my feelings." Subjects did not expect to be asked about and did not voluntarily share their hypoglycemic experiences.

\section{DISCUSSION}

The primary aim of this study was to allow 20 young adults with type 1 diabetes to tell their stories of living with hypoglycemia so that physicians and other health care professionals could better understand their everyday experience. Through these personal accounts, common themes and concerns were identified. Hypoglycemia was described as creating conflicts in interpersonal relationships and negatively influencing subjects' feelings of autonomy, competence, control, and sense of themselves. Hypoglycemia was also described as an extremely private experience that was not openly inquired about or discussed.

Through the use of narratives in this study, we heard and understood more about the subjective experiences of hypoglycemia. Bruner described how narratives allow for easier entry and easier identification with content than expository writing because the "story, in a word, is a vicarious experience." 37 From these stories with their "little epiphanies of ordinariness," 38 we were allowed a close look into the feelings of helplessness and loss of control experienced by persons with hypoglycemia. Subjects stated that they rarely talked about their hypoglycemia to others, and through these personal accounts, they shared their experiences with the interviewer and the readers of this report.

There are several limitations to this study. First, the patients studied were middle-class, highly educated, and white. Second, the sample size was small, and the subjects' willingness to participate in the study may reflect a bias in their views of hypoglycemia and its effects on their everyday lives. These factors may limit the generalizability of the findings. Third, all of the interviews were conducted by one interviewer, and although there was a semistructured protocol, there can be observer bias in pursuing certain questions. Fourth, the themes were derived through qualitative analysis, and the reliability of the themes was not assessed. Finally, a cross-sectional approach that uses one interview at a single point in time is limited and may not necessarily apply across different points in time.

Preventing hypoglycemia is not an easy matter. Because of the imperfections of current insulin replacement regimens, absolute or relative insulin excess must occur from time to time in patients with type 1 diabetes. ${ }^{17}$ From the results of the Diabetes Control and Complications Trial (DCCT), ${ }^{1}$ both health care professionals and patients with diabetes are motivated to find a balance between minimizing the risks of hypoglycemia and maintaining good glycemic control. This attempt to balance intense medical control and less stressful daily living is not new to the medical management of diabetes. In his historical account of diabetes treatment, Feudtner demonstrated, through the medical records and personal letters of one of Elliott Joslin's patients, the ever-present conflict between the physician's "want for control" of diabetes and its complications and the patient's struggle to live normally and to understand his sense of self in relation to his disease. ${ }^{39}$ These same struggles were revealed through the personal accounts of the subjects in this study. Feudtner noted how Joslin's beliefs and practices of tight control were validated from the results of the DCCT, but despite these results, the questions of how far to pursue control and at what personal consequence to patients' lives remain open.

If intensive treatment lessens the possibilities of blindness, kidney disease, and neuropathies, but also increases the incidence of severe hypoglycemia and hypoglycemic unawareness, then physicians and nurses must support their patients in the effective management of hypoglycemia. It is important to emphasize that the DCCT incorporated extensive patient education and professional support. ${ }^{40}$ Patients need to be taught about hypoglycemia; decisions about tightening glycemic control need to be evaluated in light of patients' understanding and ability to manage hypoglycemic experiences in the context of their daily lives.

Blood Glucose Awareness Training is a psychoeducational program that helps patients identify their blood glucose symptoms more accurately and treat these symptoms more effectively. ${ }^{41}$ It teaches patients to differentiate between their autonomic and neuroglycopenic symptoms and how to use their neuroglycopenic symptoms as keys to recognizing hypoglycemia and to help compensate for hypoglycemic unawareness. Although this training does not explicitly provide patients with a platform to express their feelings about hypoglycemia, it is one method for making hypoglycemia a clear target of professionalpatient interchange. Diabetes empowerment programs also address the psychosocial aspects of living with diabetes as an integral part of patient care and education. ${ }^{42}$ This approach enhances patients' ability to develop realistic self-care goals, use problem-solving skills to achieve these goals, identify and obtain appropriate social support, and manage the stress of diabetes.

In the treatment of diabetes, there is an increasing emphasis on teaching physicians to ask their patients questions that are "designed to identify important areas of personal concern." ${ }^{4}$ Professional support in the management of hypoglycemia can include doctors and nurses inquiring more about the hypoglycemic difficulties patients face in their families, social life, and at work. Through this inquiry patients may feel less isolated in living with hypoglycemia, and this mutual understanding may influence patient-clinician therapeutic decisions.

Funded by Behavioral and Mental Health Research Department Funding, Joslin Diabetes Center.

\section{REFERENCES}

1. The Diabetes Control and Complications Trial Research Group. The effect of intensive treatment of diabetes on the development 
and progression of long-term complications in insulin-dependent diabetes mellitus. N Engl J Med. 1993;329:977-86.

2. Cryer PE. Iatrogenic hypoglycemia in IDDM: consequences, risk factors, and prevention. In: Marshall SM, Home PD, Alberti KGMM, Krall LP, eds. Diabetes Annual. Amsterdam, The Netherlands: Elsevier; 1993;7:317-31.

3. Gold AE, Deary IJ, Frier BM. Hypoglycaemia and non-cognitive aspects of psychological function in insulin-dependent (Type 1) Diabetes Mellitus. Diabetic Med. 1997;14:111-8.

4. Langen SJ, Deary IJ, Hepburn DA, Frier BM. Cumulative cognitive impairment following recurrent severe hypoglycaemia in adult patients with insulin-treated diabetes mellitus. Diabetologia. 1991; 34:337-44.

5. Wredling R, Levander S, Adamson U, Lins PE. Permanent neuropsychological impairment after recurrent episodes of severe hypoglycaemia in man. Diabetologia. 1990;33:152-7.

6. McCrimmon RI, Deary IJ, Huntly BJP, MacLeod KJ, Frier BJ. Visual information processing during controlled hypoglycaemia in humans. Brain. 1996;119:1277-87.

7. Reich JN, Kaspar C, Puczynski MS, et al. Effect of a hypoglycemic episode on neuropsychological functioning in diabetic children. J Clin Exp Neuropsychol. 1990;12:613-26.

8. Gonder-Frederick LA, Cox DJ, Bobbitt SA, Pennebaker JW. Mood changes associated with blood glucose fluctuations in insulin dependent diabetes mellitus. Health Psychol. 1989;8:45-59.

9. Polonsky WH, Davis CL, Jacobson AM, Anderson BJ. Correlates of hypoglycemic fear in type I and type II diabetes mellitus. Health Psychol. 1992;11:199-202.

10. Wredling RAM, Theorell PGT, Roll HM, Lins PES, Adamson UKC. Psychosocial state of patients with IDDM prone to recurrent episodes of severe hypoglycemia. Diabetes Care. 1992;15: 518-20.

11. Pramming S, Thorsteinsson B, Bendtson I, Binder C. Symptomatic hypoglycaemia in 411 type I diabetic patients. Diabetic Med. 1991;8:217-22.

12. Stewart M, Brown JB, Weston WW, McWhinney IR, McWilliam CL, Freeman TR. Patient-Centered Medicine: Transforming the Clinical Method. Thousand Oaks, Calif: Sage Publications; 1995.

13. Lazare A, Putnam SM, Lipkin M. Three functions of the medical interview. In: Lipkin M, Putnam SM, Lazare A, eds. The Medical Interview: Clinical Care, Education, and Research. New York, NY: Springer-Verlag; 1995:3-19.

14. Jacobson AM. The psychological care of patients with insulindependent diabetes mellitus. N Engl J Med. 1996;334:1249-53.

15. Geertz C. The Interpretation of Cultures. New York, NY: Basic Books; 1973.

16. McCrimmon RJ, Frier BM. Hypoglycaemia, the most feared complication of insulin therapy. Diabetes Metab. 1994;20:503-12.

17. Cryer PE, Fisher JN, Shamoon H. Hypoglycemia. Diabetes Care. 1994; 17:734-55.

18. Hyden LC. Illness and narrative. Soc Health Illness. 1997;19:48-69.

19. Borkin JM, Quirk M, Sullivan M. Finding meaning after the fall: injury narratives from elderly hip fracture patients. Soc Sci Med. 1991;33:947-57.
20. Bury M. Chronic illness as biographical disruption. Soc Health Illness. 1982;4:167-82.

21. Frank AW. At the Will of the Body: Reflections on Illness. New York, NY: Houghton Miflin; 1991.

22. Broyard A. Intoxicated by My Illness, and Other Writings on Life and Death. New York, NY: Clarkson Patter; 1992.

23. Kleinman A. The Illness Narratives: Suffering, Healing, and the Human Condition. New York, NY: Basic Books; 1988.

24. Brody H. Stories of Sickness. New Haven, Conn: Yale University Press; 1987.

25. Hunter MK. Doctors' Stories. The Narrative Structure of Medical Knowledge. Princeton, NJ: Princeton University Press; 1991.

26. Sacks O. Medicine and the narrative. Mt Sinai Med J. 1993;60: 127-31.

27. Matthews HF, Lannin DR, Mitchell JP. Coming to terms with advanced breast cancer: black women's narratives from Eastern North Carolina. Soc Sci Med. 1994;38:789-800.

28. William G. The genesis of chronic illness: narrative reconstruction. Soc Health Illness. 1984;6:175-200.

29. Mischler EG. Research Interviewing, Context and Narrative. Cambridge, Mass: Harvard University Press; 1986.

30. Frank AW. The Wounded Storyteller: Body Illness and Ethics. Chicago, Ill: Chicago University Press; 1995.

31. Conrad P. Qualitative research on chronic illness: a commentary on method and conceptual development. Soc Sci Med. 1990;30: 1257-63.

32. Zitman FG, Mennen MFG, Griez E, Hooper C. The different versions of the Hamilton depression scale. In: Bech P, Coppen A, eds. The Hamilton Scales. Heidelberg, Germany: Springer; 1989.

33. Spielberger CD. Anxiety as an emotional state. In: Speilberger CD, ed. Anxiety-Current Trends and Theory and Research. New York, NY: Academic Press; 1972.

34. Glaser B, Straus AL. The Discovery of Grounded Theory. New York, NY: Basic Books; 1967.

35. Straus AL. Qualitative Analysis for Social Scientists. New York, NY: Cambridge University Press; 1987.

36. Somer R, Somer B. A Practical Guide to Behavioral Research. 2nd ed. New York, NY: Oxford University Press; 1986.

37. Bruner J. Acts of Meaning. Cambridge, Mass: Harvard University Press; 1990.

38. Bruner J. Actual Minds, Possible Worlds. Cambridge, Mass: Harvard University Press; 1986.

39. Feudtner C. The want of control: ideas, innovations, and ideals in the modern management of diabetes mellitus. Bull Hist Med. 1995;69:66-90.

40. Cryer PE. Hypoglycemia: Pathophysiology, Diagnosis, and Treatment. Oxford, England: Oxford University Press; 1997.

41. Cox DJ, Gonder-Frederick L, Polonsky W. A multicenter evaluation of blood glucose awareness training, II. Diabetes Care. 1995; 18:523-8.

42. Anderson RM, Funnell MM, Butler PM, Arnold MS, Fitzgerald JT, Feste CC. Patient empowerment. Diabetes Care. 1995;18:943-9. 